\title{
ACUTE RENAL FAILURE IN A TERTIARY CARE CENTER IN NEPAL
}

\author{
Khakurel S*, Satyal P R*, Agrawal R K*, Chhetri P K , Hada R* \\ * Bir Hospital, Kathmandu, Nepal
}

\section{ABSTRACT}

From July 1998 to July 1999, 45 cases of acute renal failure were treated at Bir Hospital, Kathmandu. Out of which 24 were male and 21 were female. Age ranged from 11 months to 84 years with mean age being 35 years and 9 cases were below 10 years.

Four cases with pre-renal azotaemia and twenty five cases of acute tubular necrosis (ATN) accounted for $64 \%$ of all cases. These were due to gastroenteritis 10 , sepsis 6 , post surgical 1 , trauma 1 and obstretical complications 5. Multiple hornet stings were responsible for acute renal failure in 3 cases, acute urate nephropathy in 1 case and miscellaneous causes in 2 cases.

Glomerulonephritis / vasculitis accounted for $17.7 \%$, acute interstitial nephritis $4.4 \%$, haemotytic uraemic syndrome (HUS) 6.6\%, and post renal azotaemia in 6.6\% of all cases. Mean serum creatinine was 8 mg/dl, mean blood urea $190 \mathrm{mg} / \mathrm{dl}$. Eight cases were treated only conservatively, eighteen received haemodialysis, fourteen received peritoneal dialysis, three received both and two refused for dialysis. Average duration of hospital stay was $\mathbf{1 3 . 6}$ days. Out of the forty-five cases twenty-nine recovered normal renal function, ten expired, two recovered partially, two progressed to chronic renal failure and two left against medical advice. Overall mortality was $\mathbf{2 2 . 2 \%}$.

Common causes of acute renal failure in our setting were gastroenteritis (22\%) and sepsis (20\%). HUS was exclusively seen in children following bacillary dysentery. Multiple hornet stings is an important cause of acute renal failure in our country.

\section{INTRODUCTION}

Acute renal failure (ARF) is defined as acute deterioration in renal function in a patient with no preexisting renal disease where patient's life can be saved by timely intervention. It is associated with high morbidity and mortality. ${ }^{1}$ Causes of acute renal failure vary in different parts of the world and sometimes within parts of the same country. Bir Hospital being a referral center for kidney disease, this study reflects the pattern of acute renal failure in our country. The purpose of this study was to delineate the various causes of acute renal failure in our setting and its outcome.

Address for correspondence :

Dr. Sudha Khakurel

Bir Hospital, Kathmandu, Nepal

Email: s_khakurel@hotmail.com

Received Date : $4^{\text {th }}$ January, 2004

Accepted Date : $18^{\text {th }}$ May, 2005 


\section{PATIENTS AND METHODS}

Retrospective analysis of all ARF patients admitted in nephrology unit of Bir Hospital from July 1998 to July 1999 was done. Criteria for diagnosis of acute renal failure was acute deterioration in renal function with serum creatinine more than $2 \mathrm{mg} / \mathrm{dl}$ and presence of normal sized kidneys or hydronephrotic kidneys with normal cortical thickness on ultrasonography. Chronic renal failure and acute on chronic renal failure were excluded from the study.

All patients were evaluated clinically at presentation and urine and blood samples were collected for routine urine analysis, complete blood count and estimation of blood urea, serum creatinine, sodium and potassium. Abdominal ultrasonography was done later.

Urinary sodium and specific gravity were estimated to differentiate pre-renal azotaemia from acute tubular necrosis in some cases. Urine culture, blood culture were done in patients with fever. Urine for occult blood was done in selected cases of myoglobinuria/haemoglobinuria. Kidney biopsy was done in cases with interstitial nephritis. Among 8 patients with gloemerulonephritis (GN) kidney biopsy was done in 3 patients, 1 patient refused biopsy, 2 patients - one with Takayasu's arteritis and one with rapidly progressive glomerulonephritis (RPGN) expired during treatment before biopsy and 2 patients were diagnosed clinically as post infectious glomerulonephritis and Henoch- Schonlein Purpura (HSP) nephritis.

\section{RESULTS}

Forty-five patients were admitted with ARF during the study period as shown in Table I. Gastroenteritis was the leading cause of ARF affecting 10 (22.2\%) patients with prerenal azotaemia in 3 cases and acute tubular necrosis (ATN) in 7 cases. Other causes included septicaemia 6 (13.3\%), GN 8 (17.7\%), obstretical 5 (11.1\%), hornet stings $3(6.6 \%)$, haemolytic uremic syndrome (HUS) $3(6.6 \%)$, obstructive uropathy $3(6.6 \%)$, surgical $2(4.4 \%)$, interstitial nephritis $2(4.4 \%)$, miscellaneous 2 (4.4\%) and urate nephropathy $1(2.2 \%)$.

Septicemia was due to necrotizing fascitis (1), typhoid fever (1), ascending cholangitis due to common bile duct stone (1), pneumonia (1), and source of infection was not clear in two cases.

Obstetrical cases were related to uro-sepsis (1), septic abortion (2), excessive bleeding following induced abortion (1), eclampsia with intrauterine death, postpartum hemorrhage and use of nephrotoxic drug in 1 case. Two cases had retained product of conception and one had disseminated intravascular coagula- tion (DIC). Surgical causes were related to cholecystectomy, common bile duct exploration and use of nephrotoxic drug in one case and another patient had a history of trauma with multiple fractures and evidence of rhadomyolysis.

Sting by a swarm of hornets caused ARF in three cases. Immediate unconsciousness was followed by dark red urine and oliguria within 24 hours in two cases and persistent vomiting led to dehydration and ATN in one case. Acute urate nephropathy followed treatment for chronic myeloid leukaemia in one case. Two miscellaneous cases were related to excessive alcohol consumption with vomiting and dehydration in one and infection with vomiting in another.

Three patients with GN were children below 13 years, the causes being post infectious glomerulonephritis in one, HenochSchonlein purpura nephritis in one and vasculitis involving renal and cerebral vessel (Takayasu's arteritis) in one. Others were biopsy proven cresentic glomerulonephritis in 1 and membrano proliferative glomerulonephritis (MPGN) in 2 and clinical RPGN in 2 cases. Hypertension was present in MPGN, HSP nephritis and vasculitis.

Interstitial Nephritis was infection related in one and Non Steriod Anti-inflamatory Drug (NSAID) induced in one case. Haemolytic uraemic syndrome occurred in children below one year and was related to bacillary dysentery in all cases. Post renal azotaemia was due to carcinoma of cervix in two cases and carcinoma of urinary bladder in one case.

Presenting symptoms were fever $28 \%$, oliguria $73 \%$, anuria $17 \%$ uraemic symptoms $68 \%$, fluid overload $33 \%$, dehydration $11 \%$, acidosis $24 \%$, hypertension $8 \%$, encephalopathy $8 \%$, fits $4 \%$, hemi paresis $2 \%$, jaundice $4 \%$, rash $2 \%$ and multiple sting marks $6 \%$.

Mean serum creatinine was $8 \mathrm{mg} / \mathrm{dl}$ and mean blood urea 190 $\mathrm{mg} / \mathrm{dl}$. Hyponatremia $(\mathrm{Na}<130 \mathrm{meq} / \mathrm{L})$ was found in 7 cases, hyperkalaemia $(\mathrm{K}>5.5 \mathrm{meq} / \mathrm{L})$ in 10 cases. Hypokalaemia below $3 \mathrm{mmol} / \mathrm{L}$ were mostly associated with diarrhoeal ARF. $\mathrm{Hb}<10 \mathrm{gm} / \mathrm{dl}$ was seen in 16 cases, WBC over 12,000/ cmm in 14 cases and very high $\mathrm{WBC}>50,000 / \mathrm{cmm}$ in one case of chronic myeloid leukemia. HUS cases were associated with raised $\mathrm{WBC}$, low platelets and evidence of haemolysis on peripheral smear. Raised fibrin degradation products with low platelets were found in an obstetrical case with sepsis and DIC. Hyperbilirubinaemia was found in three cases. Ultrasonography of abdomen showed normal sized kidneys with normal or slightly raised echogenicity in all patients except with obstructive uropathy who had hydronephrosis. CT scan revealed cerebral infarct in a patient with Takayasu's vasculitis. 
Table I: Aetiology and outcome of ARF

\begin{tabular}{|c|c|c|c|c|c|c|}
\hline & No & $\mathbf{C R}$ & PR & NR & $\mathbf{E X}$ & RT \\
\hline Gastroenteritis & 10 & 9 & - & - & 1 & - \\
\hline Sepsis & 6 & 2 & - & 1 & 3 & - \\
\hline Obstetrical & 5 & 3 & - & 1 & 1 & - \\
\hline Surgical & 2 & 1 & - & - & 1 & - \\
\hline Hornet stings & 3 & 2 & - & - & 1 & - \\
\hline Urate nephropathy & 1 & - & - & - & 1 & - \\
\hline Miscellaneous & 2 & 2 & - & - & - & - \\
\hline GN / vasculitis & 8 & 5 & - & - & 2 & 1 \\
\hline Interstitial nephritis & 2 & 2 & - & - & - & - \\
\hline HUS & 3 & 3 & - & - & - & - \\
\hline Post Renal & 3 & - & 2 & - & - & 1 \\
\hline Total & 45 & 31 & 2 & 2 & 10 & 2 \\
\hline
\end{tabular}

\section{Treatment and Outcome}

Patients with pre-renal azotemia were treated with fluid replacement only. Supportive treatment was given to all patients. Dialysis therapy was given to $35(77 \%)$ cases. 18 patients received haemodialysis, 14 patients received peritoneal dialysis, 3 patients received peritoneal dialysis followed by haemodialysis and two patients including one RPGN and vasculitis refused dialysis treatment.

All patients of ARF due to GN were treated initially with pulse methyl prednisolone (0.5-1 gm/day) for three days followed by other immunosuppressives as follows.

MPGN, crecentic GN, clinical RPGN and Takayasu's arteritis were treated with prednisolone $1 \mathrm{mg} / \mathrm{kg} /$ day and cyclophosphamide $2 \mathrm{mg} / \mathrm{kg} /$ day, HSP nephritis was treated with Prednisolone $1 \mathrm{mg} / \mathrm{kg} /$ day and azathioprine $1.5 \mathrm{mg} / \mathrm{kg}$ and post infectious glomerulonephritis was treated with prednisolone $1 \mathrm{mg} / \mathrm{kg} /$ day.

Out of the forty-five cases twenty-nine (64\%) recovered normal renal function, 2 (4\%) with obstructive uropathy had partial recovery, 2 (4\%) progressed to CRF due to cortical necrosis and $2(4 \%)$ refused treatment (Table I). Overall mortality was $22 \%$.

\section{DISCUSSION}

In contrast to developed countries where most cases of ARF are related to surgery and trauma in intensive care units, ${ }^{2} \mathrm{ARF}$ in developing countries are related to medical causes. Our present study showed medical causes to account for $77 \%$ of cases, gastroenteritis being the leading cause. This is slightly higher than the observation in Bangladesh, ${ }^{3}$ Pakistan ${ }^{4}$ and North India ${ }^{5}$ where over $60 \%$ cases are related to medical causes with gastroenteritis being the commonest one. Outcome of gastroenteritis was good with only $10 \%$ mortality. Next important cause was sepsis with high mortality around $50 \%$ and cortical necrosis leading to CRF in $16 \%$. High mortality in this group was probably related to delay in initiating dialysis treatment in 2 cases and presence of co-existing chronic obstructive pulmonary disease in one case. Cases of RPGN and vasculitis (Takayasu's arteritis) had poor prognosis with $25 \%$ mortality and non recovery of renal function in $12.5 \%$. Takayashu's arteritis has been described as the commonest cause of renovascular hypertension in North India. ${ }^{6}$ Our case was a 5 year old girl with fever, refractory hypertension, hemiplegia and ARF. ARF due to multiple wasp and hornet stings has been described from different parts of the world including India ${ }^{7}$ and Sri Lanka. ${ }^{8}$ Out of 3 cases of hornet stings causing ARF, myoglobinuria/ haemoglobinuria was responsible in two cases while third case had multiple factors including persistent vomiting. One of the three cases expired due to fluid overload. Haemolytic uraemic syndrome $^{9}$ is considered a benign disease in infants with a diarrhoeal episode in the prodromal phase, short period of oligoanuria and no hypertension. Three of our HUS cases were children with diarrhoeal prodrome, oliguria lasting 1-2 weeks and complete recovery of renal function.

Overall recovery of renal function was $71 \%$ in the medical group with mortality around $22 \%$ and progression to CRF in $2.8 \%$. Although ARF has become a very rare complication of pregnancy in developed countries ${ }^{10}$ as a result of disappearance of septic abortion and improvement in perinatal care, it continues to be common in developing countries. ${ }^{11}$ Obstetrical cases with ARF constituted $11 \%$ of all cases in our study and related to induced abortion and sepsis. Obstetrical group showed complete recovery of renal function in $60 \%$, acute cortical necrosis leading to chronic renal failure in $20 \%$ and mortality in $20 \%$ 
which is higher in comparison to Bangladesh (7.6\%) and Sri Lanka (10\%) and similar to Pakistan (23\%).

\section{CONCLUSION}

The commonest cause of ARF in our setting was gastroenteritis followed by sepsis and gloemerulonephritis. HUS was exclusively seen in children following bacillary dysentery. Multiple hornet stings in an important cause of ARF in our country. Overall mortality of $22 \%$ is comparable to other South Asian countries.

\section{REFERENCES}

1. Firth JD. The clinical approach to the patient with acute renal failure. In: Davision AM, Cameron JS, Grunfeld JP, Kerr DNS, Ritz E and Winearls CG, eds. Oxford Textbook of clinical Nephrology Vol II, Second edition, Oxford: Oxford University Press, 1998; 1578-1579.

2. Wheeler DC et al. High risk acute renal failure. Q J Med. 1986; 61(234): 977 - 984.
3. Rashid HU et al. Acute renal failure in adult in a teaching hospital. Bangladesh Renal J. 1997; 16(2): 41-44.

4. Naqvi $R$ et al. Analysis of factors causing acute renal failure. JPMA J Pak Med Assoc. 1996; 46(2): 29-30.

5. Prakash J et al. Acute Renal failure in Eastern India. Nephrol Dial Transplant. 1995; 10(11) 2009-12.

6. Chugh KS, Jain S, Sakhuja V, et al. Renovascular hypertension due to Takayasu's arteritis among Indian patients. Q J Med. 1992; 85:307.

7. Chugh KS et al. Acute renal failure following multiple hornet stings. Nephron. 1988; 49(4): 319-21.

8. Ramachandran SK. Acute renal failure in Sri Lanka. Proceedings of the $5^{\text {th }}$ Asian Pacific congress of nephrology. 1992; 40: 378-382.

9. Habib R. Primary haemolytic uraemic syndrome. Proceedings of the $5^{\text {th }}$ Asian Pacific congress of Nephrology.1992; 34:319-328.

10. Pertuiset N, Grunfeld JP. Acute renal failure in pregnancy. Clin Obstet Gynaecol. 1987; 1(4): 873-90.

11. Naqvi R et al. Acute renal failure of obstetric origin during 1994 at one centre. Ren fail. 1996; 18(4): 681-3. 